NASA Technical Memorandum 102411

\title{
Density of Intercalated Graphite Fibers
}

James R. Gaier

Lewis Research Center

Cleveland, Ohio

and

Melissa E. Slabe

Cleveland State University

Cleveland, Ohio

December 1989 
- 


\title{
DENSITY OF INTERCALATED GRAPHITE FIBERS
}

\author{
James R. Gaier \\ NASA Lewis Research Center, Cleveland, OH 44135 \\ Melissa E. Slabe \\ Cleveland State University, Cleveland, OH 44115
}

\begin{abstract}
The density of Amoco P-55, P-75, P-100, and P-120 pitch-based graphite fibers and their intercalation compounds with bromine, iodine monochloride, and copper (II) chloride have been measured using a density gradient column. The distribution of densities within a fiber type is found to be a sensitive indicator of the quality of the intercalation reaction. In all cases the density was found to increase, indicating that the mass added to the graphite is dominant over fiber expansion. Density increases are small (less than 10 percent) giving credence to a model of the intercalated graphite fibers which have regions which are intercalated and regions which are not.
\end{abstract}

\section{INTRODUCTION}

Carbon and graphite fibers are being used increasingly in aerospace applications where high strength, high stiffness, and low weight is required. In some of these applications, such as airframes and control surfaces, the application of this technology has been hampered by the low conductivity of these materials with respect to the metallic components they are replacing. Intercalation, or the insertion of guest atoms or molecules into the graphite lattice, is one promising scheme to improve the conductivity of the fibers without seriously degrading their desirable properties [1]. 
The application of composites of intercalated graphite fibers is also being actively pursued in order to take advantage of other unique properties. Intercalation can be used to enhance mechanical properties such as vibrational damping [2] and interlaminar shear strength [1] or to enhance composite electrical properties [3] for applications ranging from electromagnetic interference shielding [4] to aircraft anti-icing/de-icing [5].

In order to successfully utilize graphite fibers for structural components they must be embedded in either a plastic, ceramic, or metal matrix. To evaluate the properties of these composite materials the fraction of the composite which is fiber and that which is matrix must be accurately determined. The standard technique to determine the volume fraction of the fiber is to measure the density of the composite, and calculate the volume fraction from the density of its component parts. Density data have already been established for Amoco P-100 fibers intercalated with bromine $\left(\mathrm{Br}_{2}\right)[6]$ and copper (II) chloride $\left(\mathrm{CuCl}_{2}\right)$ [7]. In this study we extend these studies to include three additional pitch-based graphite fibers (P-120, P-75, and P-55) and two additional intercalates (iodine monochloride (ICl), and nickel (II) chloride $\left(\mathrm{NiCl}_{2}\right)$ ).

\section{METHODS AND MATERIALS}

Fibers used in this study were Thornel P-120, P-100, P-75, and P-55 purchased from Amoco Performance Products (Parma, OH). As a consequence of Amoco' efforts to improve the mechanical properties of its graphite fibers, there has been a significant change in the electrical properties of its fibers, especially in P-75. Because of this, intercalation compounds from two batches of P-75, those purchased in 1984 ("old P-75") and those purchased in 1987 ("new P-75") have been evaluated and are separately reported herein. 
The P-120, P-100, and P-75 fibers were intercalated with $\mathrm{Br}_{2}$ using a room temperature, vapor-phase reaction. The fibers were intercalated for about 24 hours, well beyond the time required for complete intercalation [8]. The fibers were allowed to degas from the $\mathrm{Br}_{2}$ for at least three days, long enough to obtain equilibrium [8]. $\mathrm{Br}_{2}$ will not intercalate P-55 fibers under these conditions. If, however, the temperature is lowered to about $0{ }^{\circ} \mathrm{C}$, an intercalation compound is formed [9]. This procedure was used in this study. None of the $\mathrm{Br}_{2}$ intercalation compounds exhibited staging by x-ray diffraction.

The fibers were intercalated with $\mathrm{ICl}$ using a vapor-phase reaction at $50^{\circ} \mathrm{C}$. Using the $\mathrm{Br}_{2}$ reaction dynamics as an analogy, the fibers were reacted for about 24 hours, and allowed to degas for at least 3 weeks. This is about three times longer than the time period to come to equilibrium [8]. These fibers also showed no staging by $\mathrm{x}$-ray diffraction.

Fibers intercalated with $\mathrm{CuCl}_{2}$ and $\mathrm{NiCl}_{2}$ were kindly provided by Intercal Company (Port Huron, MI). P-55 fibers did not significantly react with $\mathrm{NiCl}_{2}$, so these fibers were not measured. X-ray diffraction determined the $\mathrm{CuCl}_{2}$ intercalation compounds to be mostly stage 2, and the $\mathrm{NiCl}_{2}$ to be mostly stage 3 . Both of these reagents form compounds which probably had undergone some decomposition due to a reaction with atmospheric water by the time of their density determination [10]. This may well have adversely affected the density measurements, both in terms of the average density and in the breadth of the distribution of densities.

The resistivities of each of the fibers are shown in Table I. All exhibited resistivity decreases over pristine fibers, which was taken as a sign of intercalation. Resistivity values for $\mathrm{CuCl}_{2}$ and $\mathrm{NiCl}_{2}$ intercalated fiber were considerably higher than those reported earlier [11][12]. This is probably due to decomposition during the time interval between intercalation and measurement, which was several weeks. 
The density columns were made up from mixtures of carbon tetrachloride $\left(\mathrm{CCl}_{4}\right)$, which has a density of $1.5940 \mathrm{~g} / \mathrm{ml}$, and bromoform $\left(\mathrm{CHBr}_{3}\right)$, which has a density of 2.8899 $\mathrm{g} / \mathrm{ml}$. Instead of mixing pure $\mathrm{CCl}_{4}$ and $\mathrm{CHBr}_{3}$ in varying amounts, binary mixture $\mathrm{e}^{\mathrm{S}}$ were used as starting fluids. This allowed for higher resolution columns. The columns were formed in $50 \mathrm{ml}$ burets so that the $\mathrm{ml}$ markings along the tube walls could be used to reference the equilibrium depths of both samples and standards. The formation of the density gradient column is illustrated in Figure 1.

The density gradient columns created using this technique are not linear. The columns were calibrated using commercially prepared and calibrated standards which ranged from about 1.8 to $2.7 \mathrm{~g} / \mathrm{cm}^{3}$ in increments of about $0.05 \mathrm{~g} / \mathrm{cm}^{3}$. The standard densities were known to the nearest $0.0001 \mathrm{~g} / \mathrm{cm}^{3}$. Extrapolations between the standards were calculated using a cubic spline. Typical resolution of the column was $0.001 \mathrm{~g} / \mathrm{cm}^{3} / \mathrm{mm}$ column length. A typical column calibration curve is shown in Figure 2. Any columns containing calibration curves with large irregularities were discarded.

Before density measurements were made on the fibers, their stability in the gradient column constituents was assessed. The resistivity of fibers soaked in $\mathrm{CCl}_{4}, \mathrm{CHBr}_{3}$, and a 50 percent binary mixture was monitored for each of the fiber types over several days. The tests were complicated by the fact that the paint used to make the electrical contacts to the fibers is soluble in the test solutions. A change of less than 5 percent in resistivity was taken as evidence that there was no significant interaction between the fibers and the solvents. The results of the tests are summarized in Table II.

Short lengths of individual filaments ( $2-4 \mathrm{~mm}$ long) were cut and dropped into the density gradient column. They were allowed to equilibrate for $12-24$ hours before their positions within the column were recorded. The fibers were suspended in a variety of 
orientations. Their orientation varied from being suspended horizontally in the column, through arbitrary angles, to vertical suspension. This is thought to be the result of a distribution of densities within the individual filaments. Since the filaments were sometimes stretched over a few graduations within the column, the position of the center of the filament was taken as the average filament density.

\section{RESULTS AND DISCUSSION}

The measured densities and their standard deviations of all of the fibers tested are summarized in Table III. Average densities are reported only to the nearest $0.01 \mathrm{~g} / \mathrm{cm}^{3}$ even though the resolution of the measurement was about an order of magnitude higher than that. This is because the sample distribution is so broad as to make further refinements meaningless. As was discussed above, there appear to be density variations greater than $0.001 \mathrm{~g} \backslash \mathrm{cm}^{3}$ within individual fibers which are only a few $\mathrm{mm}$ in length.

The first column of Figure 3 shows the histograms of the pristine fiber density for each of the fiber types tested. The standard deviation of pristine fiber densities varies from 0.1 to 0.6 percent of the fiber density with no trend on modulus. The densities ranged from 90 to 97 percent of the crystallographic density of $2.2535 \mathrm{~g} / \mathrm{cm}^{3}$, consistent with models which describe the fibers as containing regions of graphite and regions of disordered carbon. P-120 and P-100 fibers have similar densities which are the highest. The densities of both old and new P-75 fibers were somewhat lower. The P-55 fiber density was higher than expected, higher than the P-75. This could be due to impurities in the fibers, especially if the impurities are metallic.

These data are plotted with the resistivity data in Figure 4. Shown also in this figure is the least squares line through the P-120, P-100, and P-75 points. Using the P-55 resistivity 
value results in an estimation of the P-55 density of about $1.98 \mathrm{~g} / \mathrm{cm}^{3}$. If the contaminant has a density of $8.0 \mathrm{~g} / \mathrm{cm}^{3}$, this would imply a 1.2 percent concentration of it, slightly higher than the less than one percent estimate given by the manufacture for non-carbon atoms. Note that the "new P-75" density is substantially lower than the "old P-75" density, and that its resistivity is substantially higher. This points to lower graphitzation on the "new P-75" fibers.

Density studies have also been undertaken with vapor-grown graphite fibers [13]. Pitch-based fibers have much less variation in their density due, at least in part, to the maturity of the technology, compared with vapor-grown fibers. It is interesting to note that even though the vapor-grown fibers have resistivities which are lower by about a factor of three, the pitch-based fibers have higher average densities. Since one would expect resistivity and density would be directly related, this may imply that there are more voids in vapor-grown fibers, and that the pitch-based fibers contain disordered carbon which contributes to its density, but not substantially to its conductivity.

The density of all of the fibers which were intercalated increased over the pristine value. Figure 3 shows the histograms for all of the fiber types tested. As the histograms are scanned along the direction of increasing fiber modulus, note that the density increases. This trend is due to the density increase of the graphite fiber host, as described above. From the density of the intercalates, shown in Table IV, if the volume of intercalate were the same, one would expect the fiber densities to vary in ascending order from $\mathrm{Br}_{2}<\mathrm{ICl}$ $<\mathrm{CuCl}_{2}<\mathrm{NiCl}_{2}$. This is clearly not the case. The order, surprisingly, depends upon the modulus of the fiber. Thus, the amount of intercalate within each fiber type differs, and not in a regular way. 
When resistivity is used as a criteria, the amounts of $\mathrm{Br}_{2}$ and $\mathrm{ICl}$ which enter the fiber is very reproducible, but there has been considerable variation in the amount of $\mathrm{CuCl}_{2}$, depending upon the reaction conditions. We only have tested one batch of $\mathrm{NiCl}_{2}$ intercalated fibers, and so cannot comment further on its reproducibility.

There was less $\mathrm{NiCl}_{2}$ in the fibers than other intercalates. Even though it has the highest density, its intercalation compounds had the lowest density. This would also account for their relatively high resistivity. The $\mathrm{NiCl}_{2}$ may also have reacted with the density gradient solvent (see Table II). Lattice expansion during intercalation followed by solvation of much of the nickel chloride into the solvent could lead to low density values. The P120 fibers showed a wide distribution of densities leading one to suspect either poor initial intercalation or desorption during the measurement process. The thermal stability of $\mathrm{NiCl}_{2}$ intercalation compounds has been shown to decrease with increasing fiber graphitization [10]. If this is a general stability trend, then it is possible that only the P-75 fibers can support an intercalation compound with $\mathrm{NiCl}_{2}$ which is stable in these solvents.

$\mathrm{CuCl}_{2}$ intercalation compounds of all four fiber grades showed similar densities. The distribution of densities in the P-120 fiber was quite broad, however, leading to suspicions about its stability in the solvent media. The densities in the P-100 fiber were somewhat lower than those reported earlier [7]. Those fibers were intercalated under different conditions. The tendency of $\mathrm{CuCl}_{2}$ intercalated fibers to extract water from the air and to subsequently deintercalate also is cause for concern. The deintercalation process may well have begun before the density measurements were begun.

The intercalation compounds of $\mathrm{ICl}$ increased in density with fiber modulus. The distributions were narrow in the P-75 and P-120 cases, indicating uniform reactions. The distribution in P-55 and P-100 were somewhat wider. The broadness of the distribution in 
the case of P-55 may be due to the lower quality of the fibers. Fibers with graphitization much lower than P-55 will not intercalate, so perhaps some of the individual filaments in P-55 will not either. It is apparent from the distribution in the P-100 and P-120 cases that some of the fibers intercalated to a greater extent than others.

The density of $\mathrm{Br}_{2}$ intercalated fibers, which should be the lowest of the fibers tested, was often among the highest instead. This implies more $\mathrm{Br}_{2}$ incorporated within the lattice. The density distributions all of the fibers, except "old" P-75, were quite narrow, indicating complete reaction. The density increases from P-55 through P-100, with P-120 densities being slightly lower, probably an artifact of a relatively small number of fibers.

If assumptions are made about the fiber expansion, the number density of intercalate molecules can be calculated. If zero expansion is assumed (certainly an incorrect assumption) then an upper limit of the atomic number density can be calculated. It can be seen from Table $\mathrm{V}$ that the result is very dilute compounds. Studies with bromine have suggested that, at least in that case, there are substantial regions within the fiber where the bromine concentration is very low, perhaps even zero [14].

When advocating the use of intercalated graphite for various application the density resistivity product has often been cited as a useful figure of merit. Usually the density of graphite has been used for the density of the intercalation compound. Although this density is obviously low, the results of this study indicate that it is low only by less than 10 percent, probably within the error of such arguments.

Of more importance is accurately knowing the density when determining the relative contribution of matrix and fibers to various composite properties. This is because the density of the fibers is so close to the density of polymers often used to make up these composites (typically 1.2 to $1.7 \mathrm{~g} / \mathrm{cm}^{3}$ ). Thus a small error in the density becomes a large 
error in the volume fraction. This could lead to large errors in the measurement of composite properties.

\section{CONCLUSIONS}

The density gradient column technique has been shown to be a practical and accurate way to determine the density of intercalated graphite fibers. Precautions must be taken to ensure that the fibers do not react with the density determining solutions. The technique gives density data on individual filaments, allowing the breadth of the distribution to be utilized to assess the quality of the intercalation reaction. Densities can be determined to a precision much higher than the uniformity of the manufacturing process for even the pristine fibers.

Intercalation by $\mathrm{Br}_{2}, \mathrm{ICl}, \mathrm{CuCl}_{2}$, and $\mathrm{NiCl}_{2}$ were all found to increase the fiber density in all cases studied by no more than about 10 percent for P-55, P-75, P-100 and P-120 pitchbased graphite fibers. Thus, even though there may be an expansion of the fiber, it does not have as much effect as the additional mass added to the fiber. These densities will see their greatest utility in composite formulation. Accurate densities are required to determine percent fiber volume, and to predict composite mechanical, electrical, and thermal properties. However, the small density increases resulting from intercalation should cause minimal impact on their application considerations. 


\section{REFERENCES}

1. D.A. Jaworske, R.D. Vannucci, and R. Zinolabedini, J. Comp. Mat. 21 (1987) 580.

2. G.A. Lesieture, A.J. Eckel, and J.A. DiCarlo, Ceram. Eng. Sci. Proc. 9 (1988).

3. J.R. Gaier, M.E. Slabe, and M. Stahl, Nineteenth Biennial Conference on Carbon, Extended Abstracts and Program, (1989) 510.

4. M.A. Centanni and E. Clark, Extended Abstracts: Graphite intercalation Compounds, Materials Research Society (1986) 219.

5. C-C. Hung, M.E. Dillehay, and M. Stahl, NASA Technical Memorandum 88888, (1987).

6. J.R. Gaier and D. Marino, NASA Technical Memorandum 87016, (1985).

7. D.A. Jaworske and J. Miller, NASA Technical Memorandum 87217, (1986).

8. J.R. Gaier, Synthetic Metals 22, (1987) 15.

9. C-C Hung and M. Long, Bull. Amer. Phys. Soc. 33, (1988) 730.

10. J.R. Gaier, M.E. Slabe, and N. Shaffer, Carbon 26, (1988), 381.

11. H. Oshima, J.A. Woollam, A. Yavroian, and H.B. Dowell, Synth. Met. 5 (1983) 113.

12. J.A. Woollam, E.J. Haugland, M.B. Dowell, A. Yavroian, A.G. Lozier, and G. Matulka, Synth. Met. 2 (1980) 309.

13. J.R. Gaier, P.D. Hambourger, and M.E. Slabe, Synthetic Metals 31, (1989) 229.

14. J.R. Gaier, accepted for publication in Synthetic Metals (1989). 
TABLE I.-INITIAL RESISTIVITIES OF

INTERCALATED GRAPHITE

FIBERS IN $\mu \Omega-\mathrm{cm}$

\begin{tabular}{|l|r|r|r|r|}
\hline Intercalatc & P-55 & P-75 & P-100 & P-120 \\
\hline Pristine & 900 & 500 & 250 & 220 \\
$\mathrm{Br}_{2}$ & 868 & 120 & 52 & 50 \\
$\mathrm{ICl}$ & 300 & 100 & 46 & 44 \\
$\mathrm{CuCl}$ & 330 & 110 & 80 & 90 \\
$\mathrm{NiCl}_{2}$ & -- & 430 & 80 & 60 \\
\hline
\end{tabular}

TABLE II --DAYS IN SOLVENT WITH NO RESISTIVITY CHANGE

\begin{tabular}{|c|c|c|c|c|}
\hline Intercalate & Fiber & $\mathrm{CCI}_{4}$ & $\mathrm{CHBr}_{3}$ & $\mathrm{CCl}_{4}+\mathrm{CHBr}_{3}$ \\
\hline Bromine & $\begin{array}{l}\text { P-55 } \\
\text { P-75 } \\
\text { P-100 } \\
\text { P-120 }\end{array}$ & $\begin{array}{r}4+ \\
16+ \\
5+ \\
47+\end{array}$ & $\begin{array}{l}1+ \\
1+ \\
5+ \\
1+\end{array}$ & $\begin{array}{l}1+ \\
1+ \\
5+ \\
5+\end{array}$ \\
\hline lodine chloride & $\begin{array}{l}P-55 \\
P-75 \\
P-100 \\
P-120\end{array}$ & $\begin{array}{c}16+ \\
-- \\
2+ \\
--\end{array}$ & $\begin{array}{l}1+ \\
-- \\
3+ \\
1+\end{array}$ & $\begin{array}{l}1+ \\
5+ \\
1+ \\
1+\end{array}$ \\
\hline Copper chloride & $\begin{array}{l}P-55 \\
P-75 \\
P-100 \\
P-120\end{array}$ & $\begin{array}{c}5+ \\
--- \\
--- \\
---\end{array}$ & $\begin{array}{l}5+ \\
--- \\
--- \\
---\end{array}$ & $\begin{array}{l}4+ \\
1+ \\
4+ \\
1+\end{array}$ \\
\hline Nickel chloride & $\begin{array}{l}P-75 \\
P-100 \\
P-120\end{array}$ & $\begin{array}{l}--- \\
<--\end{array}$ & $\begin{array}{l}--- \\
--- \\
---\end{array}$ & $\begin{array}{c}4+ \\
<1 \\
1+\end{array}$ \\
\hline
\end{tabular}

aFailure in all cases wan due to the fiber becoming detached from measurement slide.

TABLE III.-INTERCALATED GRAPHITE FIBER DENSITIES, $\mathrm{g} / \mathrm{cm}^{3}$

\begin{tabular}{|c|c|c|c|c|c|}
\hline Intercalate & P-55 & $P-75$ (new) & P-75(old) & $P-100$ & $\mathrm{P}-120$ \\
\hline Amoco spec. & 2 & 2 & 2.0 & 2.15 & 2.18 \\
\hline Pristine & $2.10 \pm 0.010$ & $2.05 \pm 0.002$ & $2.06 \pm 0.013$ & $2.16 \pm 0.007$ & $2.18 \pm 0.003$ \\
\hline Bromine & $2.17 \pm .012$ & $2.14 \pm .006$ & $2.22 \pm .018$ & $2.28 \pm .015$ & $2.24 \pm .021$ \\
\hline Iodine monochloride & $2.13 \pm .010$ & $2.18 \pm .012$ & $2.20 \pm .013$ & $2.23 \pm .036$ & $2.31 \pm .029$ \\
\hline Copper (II) chloride & $2.18 \pm .017$ & --_- & $2.26 \pm .022$ & $2.24 \pm .002$ & $2.25 \pm .015$ \\
\hline Nickel (II) chloride & -...----- & --_--- & $2.16 \pm .042$ & $2.19 \pm .015$ & $2.19 \pm .039$ \\
\hline
\end{tabular}

TABLE IV.-DENSITY OF INTERCALATES, $\mathrm{g} / \mathrm{cm}^{3}$

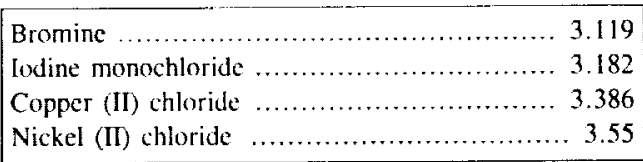

TABLE $\mathrm{V},-$ MINIMUM RATIO OF CARBON ATOMS TO INTERCALATE MOLECULES

\begin{tabular}{|l|c|c|c|c|c|}
\hline Intercalate & P-55 & P-75(new) & P-75(old) & P-100 & P-120 \\
\hline Bromine & 24 & 12 & 6 & 8 & 16 \\
Iodine monochloride & 32 & 8 & 7 & 19 & 7 \\
Copper (II) chloride & 16 & -- & 6 & 19 & 16 \\
Nickel (II) chloride & --- & -- & 13 & 99 & 99 \\
\hline
\end{tabular}




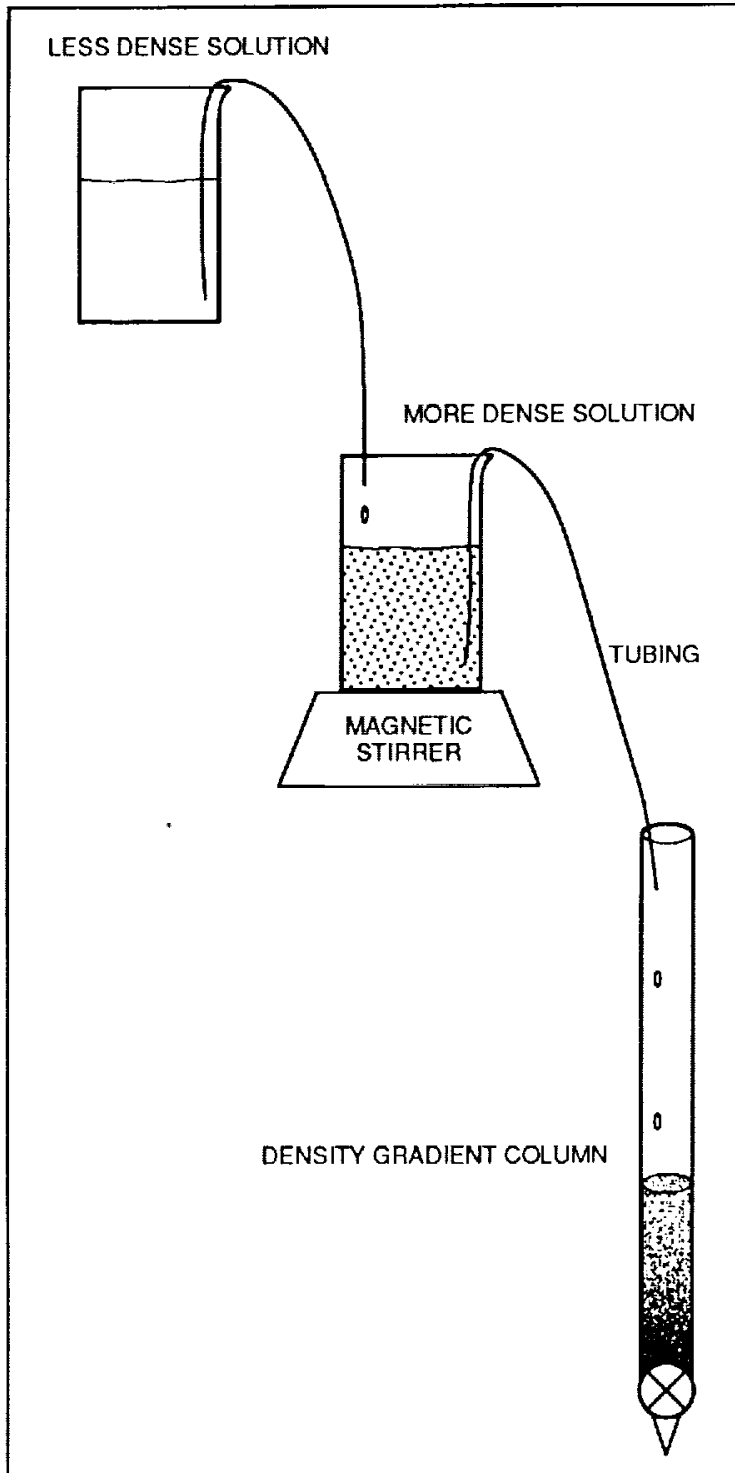

1) LESS DENSE SOLUTION IS ADDED DROP BY DROP TO MORE DENSE SOLUTION.

2) THE DENSITY OF THE MORE DENSE SOLUTION DECREASES OVER TIME BECAUSE OF THE ADDITION OF THE LESS DENSE SOLUTION

3) THE MORE DENSE SOLUTION, WHICH HAS A DENSITY DECREASING OVER TIME, IS ADDED TO THE COLUMN DROP BY DROP.

4) THE RESULT IS A COLUMN WITH DENSITY WHICH DECREASES FROM THE BOTTOM TO THE TOP OF THE COLUMN.

5) A SAMPLE PLACED IN THE COLUMN WILL SINK UNTIL IT REACHES A SOLUTION DENSITY EQUAL TO ITS OWN DENSITY.

Figure 1. - The formation of a density gradient column.

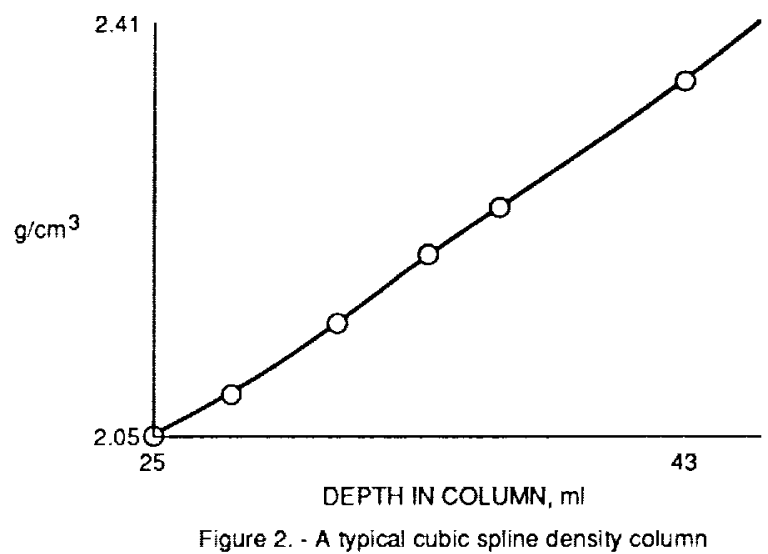
calibration curve. 

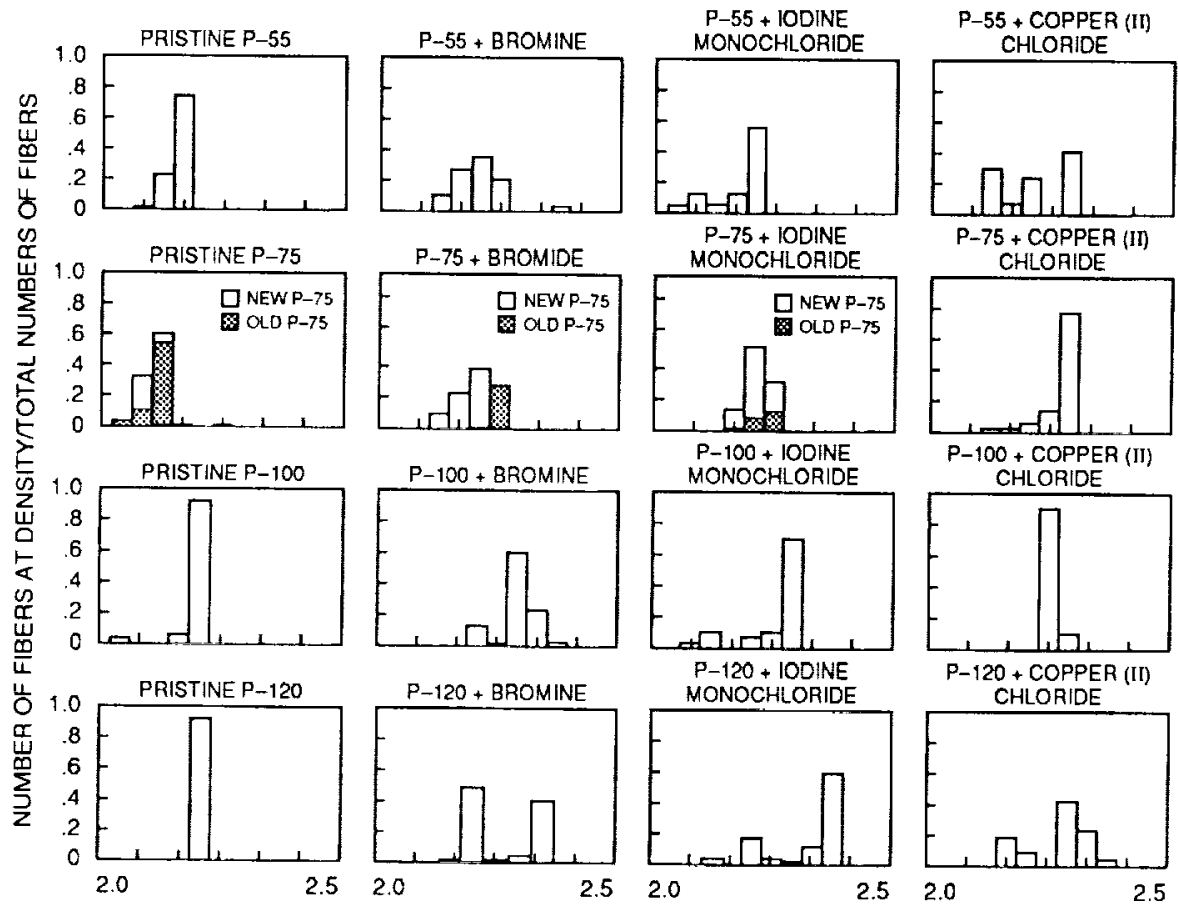

P-75 + IODINE

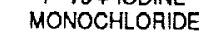

P-75 + NICKEL (II)
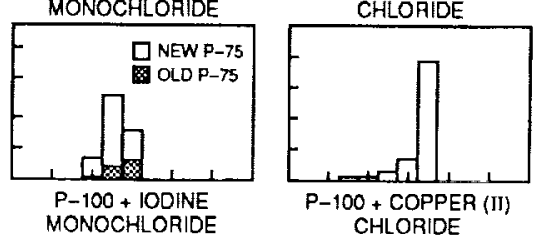
CHLORIDE

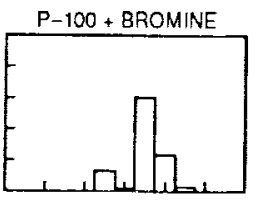

P-100+ COPPER (II) CHLORIDE
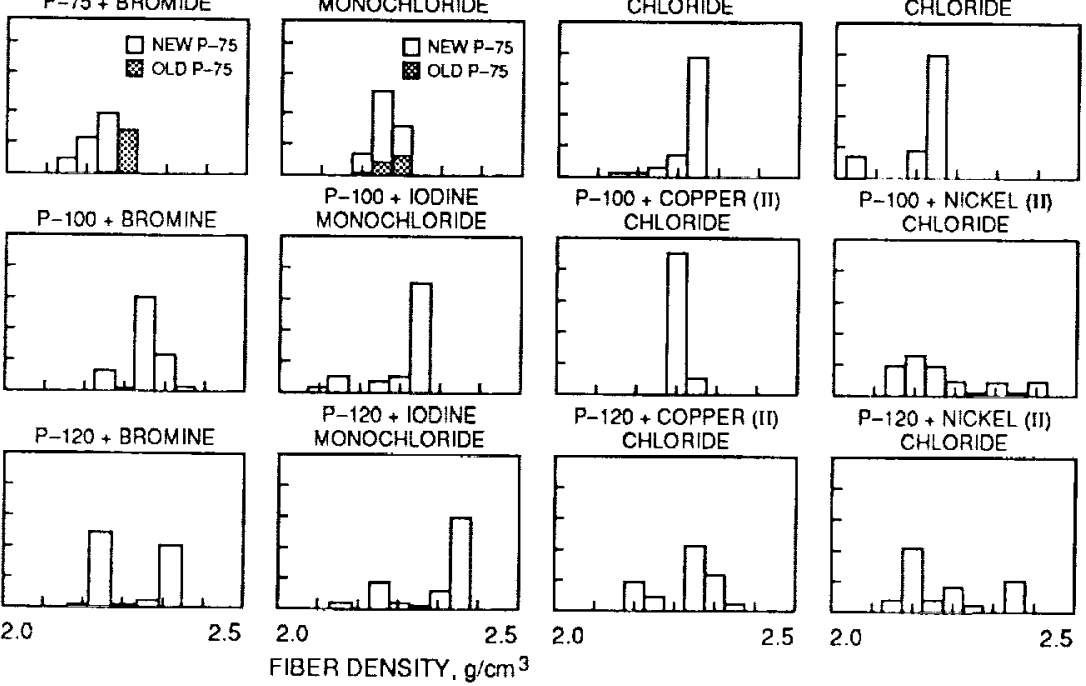

Figure 3. - Hislograms of pristine and intercalated graphite fiber density in increments of $0.05 \mathrm{~g}^{\prime} \mathrm{cm}^{3}$.

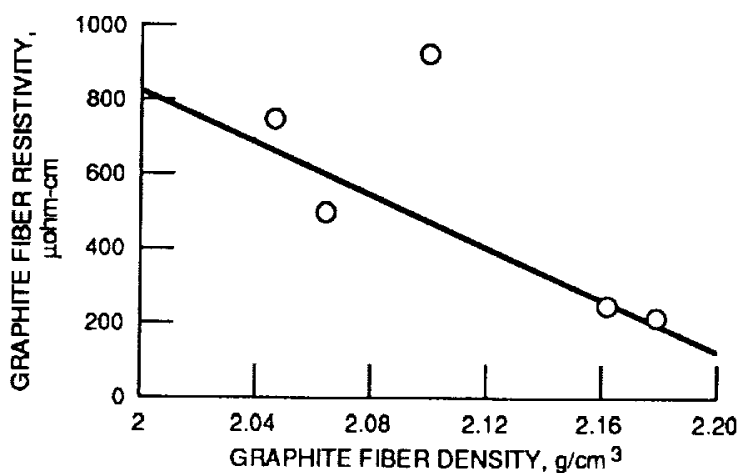

Figure 4. - Pristine fiber resistivity as a function of density. 


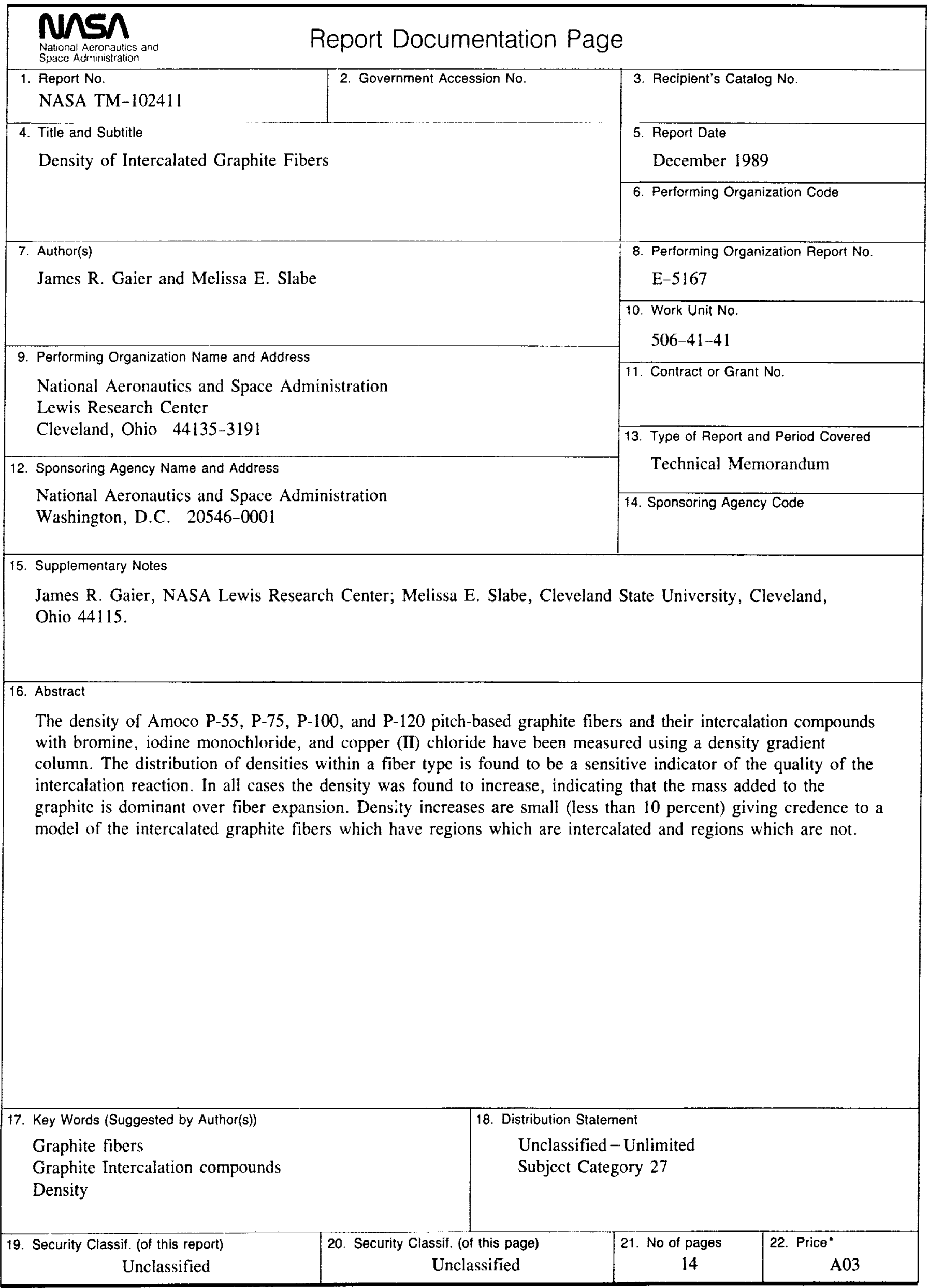

